\title{
Application of the Cropping System Model (CSM)-CROPGRO- Soybean for Determining Optimum Management Strategies for Soybean in Tropical Environments
}

\author{
P. Banterng ${ }^{1,2}$, G. Hoogenboom ${ }^{1}$, A. Patanothai ${ }^{2}$, P. Singh ${ }^{3}$, S. P. Wani ${ }^{3}$, P. Pathak ${ }^{3}$, S. Tongpoon- \\ pol $^{4}$, S. Atichart ${ }^{4}$, P. Srihaban ${ }^{5}$, S. Buranaviriyakul ${ }^{6}$, A. Jintrawet ${ }^{7}$ \& T. C. Nguyen ${ }^{8}$ \\ 1 Department of Biological and Agricultural Engineering, University of Georgia, Griffin, GA, USA \\ 2 Department of Plant Science and Agricultural Resources, Faculty of Agriculture, Khon Kaen University, Khon Kaen, Thailand \\ 3 Soils and Agroclimatology Division, International Crops Research Institute for the Semi-Arid Tropics (ICRISAT), Paatancheru, Andhra Pradesh, India \\ 4 Office of Agricultural Research and Development Region 3, Department of Agriculture (DOA), Khon Kaen, Thailand \\ 5 Land Development Department (DLD) Regional Office 5, Khon Kaen, Thailand \\ 6 Department of Agronomy, Faculty of Agriculture, Chiang Mai University, Chiang Mai, Thailand \\ 7 Department of Soil Science and Conservation, Faculty of Agriculture, Chiang Mai University, Chiang Mai, Thailand \\ 8 Legume Research and Development Center, Vietnam Agricultural Science Institute, Thanh Tri, Ha Noi, Vietnam
}

\section{Keywords}

crop simulation model; CSM-CROPGROSoybean; Decision Support System; soil; weather

\section{Correspondence \\ G. Hoogenboom \\ Department of Biological and Agricultural Engineering, University of Georgia, Griffin, GA 30223 1797, USA \\ Tel.: 1-770-228-7216 \\ Fax: 1-770-228-7218 \\ Email: gerrit@uga.edu}

Accepted October 2, 2009

doi:10.1111/j.1439-037X.2009.00408.x

\begin{abstract}
The determination of optimum crop management practices for increasing soybean production can provide valuable information for strategic planning in the tropics. However, this process is time consuming and expensive. The use of a dynamic crop simulation model can be an alternative option to help estimate yield levels under various growing conditions. The objectives of this study were to evaluate the performance of the Cropping System Model (CSM)-CROPGROSoybean and to determine optimum management practices for soybean for growing conditions in the Phu Pha Man district, Thailand. Data from two soybean experiments that were conducted in 1991 at Chiang Mai University and in 2003 at Khon Kaen University were used to determine the cultivar coefficients for the cultivars CM 60 and SJ 5. The CSM-CROPGRO-Soybean model was evaluated with data from two experiments that were conducted at Chiang Mai University. The observed data sets from farmers' fields located in the Phu Pha Man district were also used for model evaluation. Simulations for different management scenarios were conducted with soil property information for seven different soil series and historical weather data for the period 1972-2003 to predict the optimum crop management practices for soybean production in the Phu Pha Man district. The results of this study indicated that the cultivar coefficients of the two soybean cultivars resulted in simulated growth and development parameters that were in good agreement with almost all observed parameters. Model evaluation showed a good agreement between simulated and observed data for phenology and growth of soybean, and demonstrated the potential of the CSM-CROPGROSoybean model to simulate growth and yield for local environments, including farmers' fields, in Thailand. The CSM-CROPGRO-Soybean simulations indicated that the optimum planting dates from June 15 to July 15 produced maximum soybean yield in a rainfed environment. However, the planting date December 15 produced the highest yield under quality irrigation. Soybean yield was slightly improved by applying nitrogen at a rate of $30 \mathrm{~kg} \mathrm{~N} \mathrm{ha}^{-1}$ at planting. Soybean yield also improved when the plant density was increased from 20 to 40 plants $\mathrm{m}^{-2}$. The results from this study suggest that the CSM-CROPGRO-Soybean model can be a valuable tool in assisting with determining optimum management practices for soybean cropping systems in the Phu Pha Man district and might be applicable to other agricultural production areas in Thailand and southeast Asia.
\end{abstract}




\section{Introduction}

Soybean is an important agronomic crop in Thailand and other countries in south and southeast Asia. In Thailand, the major agricultural production areas of this crop are in the northern and north-eastern regions. In Phu Pha Man, a district of Khon Kaen in north-eastern Thailand, farmers commonly cultivate soybean under both rainfed and irrigated conditions. Records from the Office of Agricultural Economics of Thailand indicate that total current cropland grown for soybean in Thailand is approximately $128000 \mathrm{ha}^{-1}$, and that the average soybean yield over the past 10 years (1994-2003) has normally been lower than the expected yield levels of $1360 \mathrm{~kg} \mathrm{ha}^{-1}$. There are several factors that impact soybean production, including management practices such as cultivar use, planting date, plant density, fertilizer application, irrigation, herbicide and pesticide applications, etc. Identifying optimum crop management practices could provide valuable information for designing a strategic plan to increase soybean yield for this production area. However, this process is time consuming and expensive as it involves many years of experimental data collection.

Cropping systems are extremely complex, as there are normally multiple objectives that have to be considered for long-term sustainability (Geng et al. 1990). In recent years, several dynamic crop simulation models have been developed as a tool to support strategic decision making in agronomic research, crop production and land-use planning (Hoogenboom et al. 1992, 2004, Penning de Vries et al. 1993, Tsuji et al. 1994, 1998). These crop models have been used to evaluate agricultural production risks across a wide range of environmental conditions (Meinke et al. 1993, Meinke and Hammer 1995, Chapman et al. 2000) and to determine optimum planting dates and management factors for increasing crop yield (Egli and Bruening 1992, Aggarwal and Kalra 1994, White et al. 1995, Hunt et al. 1996). The application of systems analysis that combines both experimental field research and crop modelling to determine optimum farming practices under varying weather conditions has become more common. For instance, Soler et al. (2007a,b) used a crop simulation model to help determine the optimum planting date for maize grown off-season for a tropical environment in Brazil.

The Cropping System Model (CSM)-CROPGROSoybean was developed to simulate vegetative and reproductive development, growth and yield of soybean as a function of crop characteristics, weather and soil conditions and climatic and crop management scenarios (Jones et al. 2003). This model is part of a suite of crop growth models that comprise the Decision Support System for Agrotechnology Transfer (DSSAT) (Hoogenboom et al.
2004). The CSM model has been evaluated across a wide range of soil and climate conditions, and has been used for various applications in temperate regions (Jones et al. 2003). Recent studies have shown that the CSM-CROPGRO-Peanut model, which is also included in the DSSAT programme, can be used as a breeding tool in Thailand to help understand the Genotype $\times$ Environment interaction and related issues associated with efficient breeding programmes (Banterng et al. 2003, 2006, Anothai et al. 2008, Phakamas et al. 2008a,b). However, the lack of model evaluation has limited the application of especially the soybean model for tropical regions such as Thailand. The general goal of this research, therefore, was to evaluate the CSM-CROPGRO-Soybean model to predict potential outcomes in south-eastern Asia. Evaluation of this model would enable its use to optimize production practices for growing conditions in Thailand and other countries in southern and south-eastern Asia. The specific objectives of this study were to evaluate the ability of CSM-CROPGRO-Soybean to simulate growth, development and yield accurately under local conditions in Thailand and to propose optimum practices for soybean for growing conditions in the Phu Pha Man district, Thailand.

\section{Materials and Methods}

\section{Crop model overview}

The CSM-CROPGRO-Soybean model contained within DSSAT (Jones et al. 2003, Hoogenboom et al. 2004) simulates plant growth and development from sowing to maturity using a daily time step, and ultimately predicts yield. The physiological processes that are simulated characterize the crop's response to the major weather factors, including temperature, precipitation and solar radiation, and to soil characterizations such as the amount of extractable soil water and nutrients. Daily photosynthesis is a function of light interception and the pool of carbohydrates available for growth is estimated by daily maintenance and growth respiration. The remaining carbohydrates are partitioned to vegetative and reproductive growth as a function of the developmental phase (Boote et al. 1998). The soil water balance is calculated on a daily basis and is a function of precipitation, irrigation, transpiration, soil evaporation, runoff from the soil surface and drainage from the bottom of the profile. Soil water is distributed among different horizontal soil layers with depth increments specified by the user. The water content for any soil layer can decrease by soil evaporation, root absorption or flow to an adjacent layer (Ritchie 1998). Actual plant water uptake and transpiration are a function of atmospheric demand and the ability of a soil 
to supply water. If potential transpirational demand is higher than potential supply by the root system, a water stress factor is calculated. Water stress causes a reduction in photosynthesis and canopy development, a change in partitioning of biomass and an increase in senescence or abscission of plant material, depending on the timing and severity of the stress.

\section{Experimental details and data collection}

Experimental data collection in this study included both model calibration and evaluation. For model calibration, two soybean experiments were conducted for the cultivars CM 60 and SJ 5. The first experiment was conducted at Chiang Mai University, Thailand. Two soybean cultivars were planted on 15 November 1991, and the plant population after germination and establishment was reduced to 20 plants $\mathrm{m}^{-2}$. The second experiment was conducted at Khon Kaen University, Thailand; soybean was planted on 20 October 2003, and the plant population was reduced to 10 plants $\mathrm{m}^{-2}$ after germination and establishment. These two experiments were conducted under optimum management practices to avoid stresses from water, nutrients, pests and diseases. Data collection followed the experimental procedures for model calibration as described in IBSNAT (1988) and by Hoogenboom et al. (1999). The experimental data that were collected included plant growth and development, crop management, daily weather conditions and soil surface and profile characteristics.

Plant development was reported based on when $50 \%$ of the plants in a plot reached the following stages: R1 (plants with the first flower), R3 (plants with a pod that is $2.0-\mathrm{cm}$ long), $\mathrm{R} 5$ (plants have initiated seed growth in at least one pod) and R7 (plants with one pod yellowing). The dates of these stages were obtained by daily observations of the plants in each plot. Growth analysis data were collected 24 times for eight plants for the 1991-1992 experiment. For the 2003-2004 experiment, growth analysis data were collected for five plants at 15, 30, 45, 65 and 75 days after planting. Plant measurements that were taken included dry weight of the different plant components (stem, leaf, pod and total above ground biomass); leaf area index (LAI) and specific leaf area (SLA). In addition, pod yield and total above ground biomass were also obtained at final harvest for both experiments.

Soil properties were collected prior to planting and included bulk density; soil texture including percent sand, silt and clay; soil moisture; organic matter; $\mathrm{pH}$; nitrate $\left(\mathrm{NO}_{3}^{-}\right)$and $\left(\mathrm{NH}_{4}^{+}\right)$concentrations and exchangeable $\mathrm{P}$ and $\mathrm{K}$. Weather data, e.g. daily minimum and maximum temperatures, rainfall and solar radiation, were obtained from a weather station at the experimental site.
Crop management information that was available included planting date, row and plant spacing and plant density, as well as dates and rates of fertilizer, irrigation, herbicide and pesticide applications.

For model evaluation, the data from two soybean experiments were used. The first experiment was conducted in 1994 at Chiang Mai University for the cultivar SJ 5. Seeds were planted on 10 January 1994, with a plant density of 24 plants $\mathrm{m}^{-2}$ and with no supplemental nitrogen fertilizer, as soybean normally fixes nitrogen. The second experiment was conducted in 2002 at Chiang Mai University for the cultivar CM 60 with two planting date treatments, i.e. 2 August and 14 September 2002; the plant density was 30 plants $\mathrm{m}^{-2}$. These two experiments were also well managed to avoid water, nutrient and pest stresses. Data collection was similar to that described previously for model calibration. In addition, field data were obtained from farmers' fields during the 1999 and 2000 rainy season for further evaluation of the CSMCROPGRO-Soybean model. There were a total of eight different farmers' practices for the cultivar SJ 5 that included various planting dates and plant densities as well as supplemental nitrogen fertilizer applications.

\section{Methods of model calibration and evaluation}

The soybean model was calibrated by determining the cultivar coefficients for the two cultivars CM 60 and SJ 5. The CSM-CROPGRO-Soybean model requires 15 cultivar coefficients (Table 1) that describe the growth and development characteristics for each individual cultivar. The cultivar coefficients for each cultivar were determined through trial and error of the model and by comparing simulated and observed data, following the procedures described by Hoogenboom et al. (1999). The existing cultivar coefficients for the maturity group (MG) IX were used as a template for both cultivars at the start of the calibration because it represents the characteristics of a tropical soybean variety. During the first step, simulated annealing was used to solve for the critical short day length (CSDL) and photoperiod sensitivity (PPSEN) by fitting the simulated and observed flowering date. Subsequently, the cultivar coefficients for the duration from emergence to flowering (EMFL), flowering to beginning pod (FLSH), flowering to beginning seed (FLSD) and beginning seed to physiological maturity (SDPM) were adjusted to match the crop life cycle for the simulated and observed data. The value for maximum leaf photosynthesis rate (LFMAX) was modified to obtain a good agreement between simulated and observed dry matter accumulations. The difference between observed and simulated leaf growth was minimized by adjusting the specific leaf area coefficient (SLAVR), the time to 
Table 1 Cultivar coefficients for soybean maturity group IX and for two local soybean cultivars from Thailand

\begin{tabular}{|c|c|c|c|c|c|}
\hline \multirow[b]{2}{*}{ Cultivar trait } & \multirow[b]{2}{*}{ Acronym } & \multirow[b]{2}{*}{ Unit } & \multirow{2}{*}{$\begin{array}{l}\text { Maturity group } \\
\text { IX }\end{array}$} & \multicolumn{2}{|c|}{ Cultivar name } \\
\hline & & & & CM 60 & SJ 5 \\
\hline $\begin{array}{l}\text { 1. Critical short day length below which reproductive development } \\
\text { progresses with no day length effect }\end{array}$ & CSDL & h & 11.88 & 12.50 & 11.90 \\
\hline $\begin{array}{l}\text { 2. Slope of the relative response of development to photoperiod } \\
\text { with time }\end{array}$ & PPSEN & $h^{-1}$ & 0.34 & 0.34 & 0.34 \\
\hline 3. Time between plant emergence and flower appearance (R1) & EMFL & Photothermal day & 23 & 23 & 23 \\
\hline 4. Time between first flower and first pod (R2) & FLSH & Photothermal day & 10 & 5 & 7 \\
\hline 5. Time between first flower and first seed (R5) & FLSD & Photothermal day & 16 & 10 & 11 \\
\hline 6. Time between first seed (R5) and physiological maturity (R7) & SDPM & Photothermal day & 36.5 & 34.0 & 31.0 \\
\hline 7. Time between first flower (R1) and end of leaf expansion & FLLF & Photothermal day & 18 & 35 & 35 \\
\hline $\begin{array}{l}\text { 8. Seed filling duration for pod cohort at standard growth } \\
\text { conditions }\end{array}$ & SFDUR & Photothermal day & 23 & 25 & 25 \\
\hline $\begin{array}{l}\text { 9. Time required for cultivar to reach final pod load under optimal } \\
\text { conditions }\end{array}$ & PODUR & Photothermal day & 10 & 20 & 17 \\
\hline $\begin{array}{l}\text { 10. Maximum leaf photosynthesis rate at } 30^{\circ} \mathrm{C}, 350 \mathrm{vpm} \mathrm{CO}_{2} \\
\text { and high light }\end{array}$ & LFMAX & $\mathrm{CO}_{2} \mathrm{~m}^{-2} \mathrm{~s}^{-1}$ & 1.03 & 1.70 & 1.70 \\
\hline 11. Specific leaf area of cultivar under standard growth conditions & SLAVR & $\mathrm{cm}^{2} \mathrm{~g}^{-1}$ & 375 & 280 & 280 \\
\hline 12. Maximum size of full leaf (three leaflets) & SIZLF & $\mathrm{cm}^{2}$ & 180 & 250 & 250 \\
\hline $\begin{array}{l}\text { 13. Maximum fraction of daily growth that is partitioned to seed } \\
\text { and shell }\end{array}$ & XFRT & & 1.0 & 0.9 & 0.9 \\
\hline 14. Maximum weight per seed & WTPSD & g & 0.18 & 0.19 & 0.22 \\
\hline 15. Average seed per pod under standard growing conditions & SDPDV & Number per pod & 2.05 & 1.90 & 1.96 \\
\hline
\end{tabular}

cessation of leaf expansion (FLLF) and maximum size of full leaf (SIZLF). The maximum fraction of daily growth that is partitioned to seed and shell weight (XFRT), the duration of pod addition (PODUR), the seed filling duration for a pod cohort (SFDUR), the average number of seeds per pod (SDPDV) and the maximum weight per seed (WTPSD) were also adjusted for fitting the simulated and observed pod weight. The procedure used to estimate the accuracy of the genetic coefficients was determined by comparing the simulated values for the development and growth characters with their corresponding observed values and the values for root mean square error (RMSE) (Wallach and Goffinet 1987) and the index of agreement (d-value) (Willmott 1982). The values of RMSE and $\mathrm{d}$ indicate the degree of agreement between the predicted values with their corresponding observed values, and a low RMSE value and a d value that approach unity are desirable. The RMSE was computed using the following equation:

$$
\text { RMSE }=\sqrt{\frac{\sum_{\mathrm{i}=1}^{\mathrm{n}}\left(\mathrm{P}_{\mathrm{i}}-\mathrm{O}_{\mathrm{i}}\right)^{2}}{\mathrm{n}}}
$$

where $\mathrm{n}$ is the total number of observations, $\mathrm{P}_{\mathrm{i}}$ is the predicted value for the $\mathrm{i}$-th measurement and $\mathrm{O}_{\mathrm{i}}$ is the observed value for the i-th measurement. The index of agreement was computed using the following equation:

$$
\mathrm{d}=1-\left[\frac{\sum_{\mathrm{i}=1}^{\mathrm{n}}\left(\mathrm{P}_{\mathrm{i}}-\mathrm{O}_{\mathrm{i}}\right)^{2}}{\sum_{\mathrm{i}=1}^{\mathrm{n}}\left(\left|\mathrm{P}_{\mathrm{i}}^{\prime}\right|+\left|\mathrm{O}_{\mathrm{i}}^{\prime}\right|\right)^{2}}\right], 0 \leq \mathrm{d} \leq 1
$$

where $\mathrm{n}$ is the total number of observations, $\mathrm{P}_{\mathrm{i}}$ is the predicted value for the $\mathrm{i}$-th measurement, $\mathrm{O}_{\mathrm{i}}$ is the observed value for the $\mathrm{i}$-th measurement and $\overline{\mathrm{O}}$ is the overall mean of the observed values, $\mathrm{P}_{i}{ }_{i}=\mathrm{P}_{\mathrm{i}}-\overline{\mathrm{O}}$ and $\mathrm{O}_{\mathrm{i}}{ }=\mathrm{O}_{\mathrm{i}}-\overline{\mathrm{O}}$.

Model evaluation with the data sets from the actual experiments and the farmers' fields was also conducted to assess the performance of the CSM-CROPGRO-Soybean model. The soil fertility factor was also optimized to account for some uncertainties in soil properties that were not simulated by the model. Model performance was evaluated based on the agreement between simulated and observed data using RMSE for model evaluation with the independent data set (RMSEP) and d statistics, as well as percent mean difference.

\section{Simulations for different management scenarios}

Model simulations for different management scenarios were conducted to predict the optimum crop management practices for soybean production for the $\mathrm{Phu}$ Pha Man district. The soil surface and soil profile characteristics for seven soil series were obtained from the Department of Land Development in Thailand (Table 2). Historical weather data for 32 years, i.e. 1972-2003, were 
Table 2 Information for the top soil layer (soil depth 0-20 cm) for seven soil series that are representative of the Phu Pha Man district in Thailand

\begin{tabular}{lllllll}
\hline Soil Series & $\begin{array}{l}\text { Bulk density } \\
\left(\mathrm{g} \mathrm{cm}^{-3)}\right.\end{array}$ & $\begin{array}{l}\text { Sand } \\
\text { fraction (\%) }\end{array}$ & $\begin{array}{l}\text { Clay } \\
\text { fraction (\%) }\end{array}$ & $\begin{array}{l}\text { Silt } \\
\text { fraction (\%) }\end{array}$ & $\begin{array}{l}\mathrm{pH} \\
\text { in water }\end{array}$ & $\begin{array}{l}\text { Total } \\
\mathrm{N}(\%)\end{array}$ \\
\hline Wang Hai & 1.41 & 29.5 & 17.5 & 53.0 & 5.1 & 0.23 \\
Phu Pha Man & 1.43 & 5.6 & 53.8 & 40.6 & 8.2 & 0.16 \\
Lat Ya & 1.51 & 42.6 & 22.0 & 35.4 & 4.9 & 0.10 \\
Sa Keao & 1.72 & 76.8 & 3.8 & 19.4 & 6.6 & 0.07 \\
Ban Mi & 1.44 & 3.0 & 68.0 & 29.0 & 5.4 & 0.21 \\
Phon & 1.67 & 75.4 & 10.5 & 14.1 & 8.2 & 0.03 \\
Nong Kung & 1.44 & 3.20 & 46.1 & 50.7 & 5.8 & 0.14 \\
\hline
\end{tabular}

obtained from the Meteorological Department in Thailand. The scenarios for crop management were first defined by following both local extension recommendations and current farmers' management practices in the district of Phu Pha Man. A rainfed condition was specified for seven planting dates in the rainy season, e.g. 15 and 30 May, 15 and 30 June, 15 and 30 July and 15 August. In addition, full irrigation was applied for three planting dates during the dry season, planted on 15 and 30 December and 15 January. Three different plant density levels were used consisting of 20,30 and 40 plants $\mathrm{m}^{-2}$. Nitrogen fertilizer was applied at rates of 0 , 10,20 and $30 \mathrm{~kg} \mathrm{~N} \mathrm{ha}^{-1}$ at 20 days after planting. The same commercial cultivars, CM 60 and SJ 5, were used for the scenario simulations.

\section{Results and Discussion}

\section{Model calibration}

The cultivar coefficients for the soybean cultivars CM 60 and SJ 5 were estimated through trial and error and comparison of model simulated and experimental data. The final values for the cultivar coefficients related to vegetative and reproductive growth and development for CM 60 and SJ 5 cultivars are presented in Table 1. The estimated values for critical short day length (CSDL) for CM 60 and SJ 5 cultivars were higher than the value for the generic maturity group IX cultivar typical for tropical conditions, whereas the values for photoperiod sensitivity (PPSEN) and duration of emergence to flowering (EMFL) were the same as the original values. Both soybean cultivars had smaller values for the duration of first flower to first pod (FLSH), first flower to first seed (FLSD) and first seed to physiological maturity (SDPM) than those for the generic cultivar MG IX. To assess the accuracy of the cultivar coefficients derived from model calibration, simulated values for four of the most critical developmental stages of CM 60 and SJ 5 cultivars for the two different planting dates were compared with the corresponding observed values. A close agreement was obtained between observed and simulated values for all four developmental stages. The model predicted the dates for first flowering between -2 and +2 days of the observed dates for both cultivars. Predictions of first pod and first seed dates were between -3 and +3 days of the observed dates for cultivar CM 60, and between +1 and -1 day of the observed dates for cultivar SJ 5 . Predicted physiological maturity dates for both cultivars were also between -1 and +1 day of the observed dates (Table 3).

The coefficients for the time between first flower (R1) and end of leaf expansion (FLLF) and maximum size of full leaf (SIZLF) for both soybean cultivars were higher than that for the generic cultivar MG IX (Table 1). However, the values for specific leaf area (SLAVR) for both soybean cultivars were lower than the original value. The comparison between observed and simulated leaf growth showed that predictions of LAI at the different growth stages were also quite good for both soybean cultivars for the two planting dates. The RMSE values for LAI ranged from 0.29 to $0.65 \mathrm{~cm}^{2} \mathrm{~cm}^{-2}$ and the $\mathrm{d}$ values ranged from 0.89 to 0.98 (Table 3 ). The predictions for SLA were fair for both cultivars; the values for RMSE ranged from 34.41 to $65.50 \mathrm{~cm}^{2} \mathrm{~g}^{-1}$ and the $\mathrm{d}$ values ranged from 0.62 to 0.83 (Table 3 ).

The values for maximum leaf photosynthesis rate (LFMAX) for both soybean cultivars were higher than the value for the MG IX (Table 1), and these values were also higher than the expected genetic range reported by Boote and Tollenaar (1994). The coefficients for seed filling duration (SFDUR) and pod filling duration (PODUR) for both soybean cultivars were higher than those for MG IX. The values for maximum fraction of daily growth to pod (XFRT) and number of seeds per pod (SDPDV) were lower than those for MG IX, but maximum weight per seed (WTPSD) for both cultivars was higher than that for MG IX. Observed and simulated values were in good agreement for total biomass and pod weight at the different growth stages for both soybean cultivars for the two different planting dates (Fig. 1). The values for both RMSE and $d$ reflected that the model predicted quite well the dry weights at different growth stages of crop biomass, pods, stems and leaves for the two soybean 
Table 3 Simulated (S) and observed (O) phenology, root mean square error (RMSE) and d values for growth characteristics obtained from model calibration for the soybean cultivars CM 60 and SJ 5 for two different planting dates

\begin{tabular}{|c|c|c|c|c|c|}
\hline \multirow[b]{2}{*}{ Planting date } & \multirow[b]{2}{*}{ Crop characteristic } & \multicolumn{4}{|l|}{ Cultivar } \\
\hline & & CM 60 & & SJ 5 & \\
\hline \multirow[t]{12}{*}{15 November 1991} & Phenology & $S(D A P)$ & $\mathrm{O}(\mathrm{DAP})$ & $S(D A P)$ & O (DAP) \\
\hline & First flowering date & 41 & 39 & 41 & 39 \\
\hline & First pod date & 48 & 45 & 50 & 49 \\
\hline & First seed date & 55 & 52 & 56 & 55 \\
\hline & Physiological maturity date & 95 & 96 & 93 & 94 \\
\hline & Growth & RMSE $\left(\mathrm{kg} \mathrm{ha}^{-1}\right)$ & d-value & RMSE $\left(\mathrm{kg} \mathrm{ha}^{-1}\right)$ & d-value \\
\hline & Crop biomass & 394 & 0.98 & 405 & 0.98 \\
\hline & Pod biomass & 153 & 1.00 & 194 & 0.99 \\
\hline & Stem biomass & 449 & 0.80 & 213 & 0.98 \\
\hline & Leaf biomass & 163 & 0.95 & 190 & 0.96 \\
\hline & $\operatorname{LAl}\left(\mathrm{cm}^{2} \mathrm{~cm}^{-2}\right)$ & 0.48 & 0.90 & 0.29 & 0.98 \\
\hline & $\operatorname{SLA}\left(\mathrm{cm}^{2} \mathrm{~g}^{-1}\right)$ & 65.50 & 0.63 & 36.23 & 0.83 \\
\hline \multirow[t]{12}{*}{20 October 2003} & Phenology & $S(D A P)$ & $\mathrm{O}(\mathrm{DAP})$ & $S(D A P)$ & $\mathrm{O}(\mathrm{DAP})$ \\
\hline & First flowering date & 31 & 33 & 31 & 33 \\
\hline & First pod date & 37 & 40 & 39 & 40 \\
\hline & First seed date & 43 & 45 & 44 & 45 \\
\hline & Physiological maturity date & 80 & 79 & 78 & 79 \\
\hline & Growth & $\operatorname{RMSE}\left(\mathrm{kg} \mathrm{ha}^{-1}\right)$ & d-value & RMSE $\left(k g ~ h a^{-1}\right)$ & d-value \\
\hline & Crop biomass & 116 & 1.00 & 398 & 0.99 \\
\hline & Pod biomass & 580 & 0.96 & 736 & 0.93 \\
\hline & Stem biomass & 98 & 0.99 & 189 & 0.98 \\
\hline & Leaf biomass & 300 & 0.88 & 197 & 0.94 \\
\hline & LAI $\left(\mathrm{cm}^{2} \mathrm{~cm}^{-2}\right)$ & 0.61 & 0.90 & 0.65 & 0.89 \\
\hline & $\operatorname{SLA}\left(\mathrm{cm}^{2} \mathrm{~g}^{-1}\right)$ & 34.41 & 0.79 & 50.28 & 0.62 \\
\hline
\end{tabular}

DAP, days after planting; LAI, leaf area index; SLA, specific leaf area.

cultivars from two different planting dates. The RMSE and $\mathrm{d}$ values varied for crop biomass from 116 to $405 \mathrm{~kg} \mathrm{ha}^{-1}$ and 0.98 to 1.00 respectively; for pod from 153 to $736 \mathrm{~kg} \mathrm{ha}^{-1}$ and 0.93 to 1.00 , respectively; for stem from 98 to $449 \mathrm{~kg} \mathrm{ha}^{-1}$ and 0.80 to 0.99 , respectively, and for leaf from 163 to $300 \mathrm{~kg} \mathrm{ha}^{-1}$ and 0.88 to 0.96 , respectively (Table 3 ). At final harvest, the simulated values were also in good agreement with the observed values, and the differences ranged from $0.6 \%$ to $21 \%$ of the observed values for total crop biomass, $2 \%$ to $15 \%$ of the observed values for pod dry weight and $0.2 \%$ to $45 \%$ of the observed values for seed dry weight.

\section{Model evaluation}

The evaluation of the CSM-CROPGRO-Soybean model with experimental data collected during the 1994 dry season and the 2002 late-rainy season at Chiang Mai University indicated that the model predicted flowering and first pod dates for CM 60 and SJ 5 cultivars reason- ably well, with errors that ranged from -3 to +3 days of the observed dates. However, the prediction for the first seed and physiological maturity dates showed rather large differences from the observed dates. The model predicted the first pod dates and physiological maturity dates between -7 to -4 days and -12 to +8 days of the observed dates respectively (Table 4 ). The differences between the simulated and observed dates of these crop development stages could be in part as a result of inaccuracies during field inspection, which were caused by the variation of crop performance. The simulated values for above-ground biomass and pod weight for the cultivar CM 60 for the 2 August 2002 planting date agreed reasonably well with the observed values (Fig. 2). Simulated above-ground biomass and pod weight for the cultivar CM 60 for the 14 September 2002 planting date seemed to be in good agreement with the observed values, although it tended to underestimate. In the case of the simulation of growth for the cultivar SJ 5 for the 1994 dry season, the model appeared to overestimate 
Fig. 1 A comparison of simulated (lines) and observed (symbols) values for above-ground biomass and pod weight for the cultivars $\mathrm{CM}$ 60 and SJ 5 for $1991(a, c)$ and $2003(b, d)$ following model calibration.
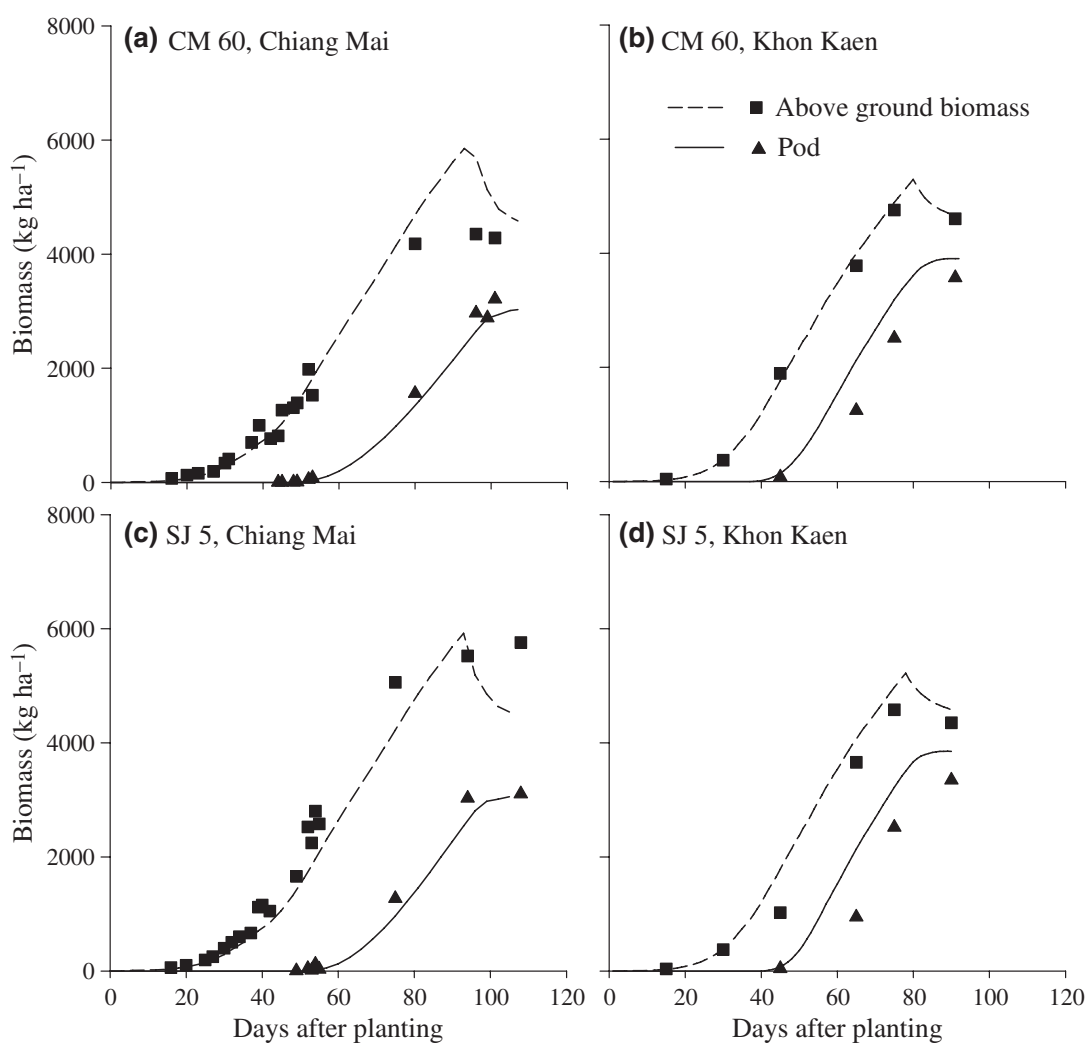

Table 4 Simulated $(\mathrm{S})$ and observed $(\mathrm{O})$ days after planting to first flowering, first pod, first seed and physiological maturity obtained from model evaluation for CM 60 cultivar for two different dates in 2002 and for the SJ 5 cultivar in 1994

\begin{tabular}{|c|c|c|c|c|c|c|c|c|c|}
\hline \multirow[b]{2}{*}{ Cultivar } & \multirow[b]{2}{*}{ Planting date } & \multicolumn{2}{|c|}{$\begin{array}{l}\text { First flowering } \\
\text { (DAP) }\end{array}$} & \multicolumn{2}{|c|}{ First pod (DAP) } & \multicolumn{2}{|c|}{ First seed (DAP) } & \multicolumn{2}{|c|}{$\begin{array}{l}\text { Physiological } \\
\text { maturity (DAP) }\end{array}$} \\
\hline & & $S$ & 0 & $S$ & $\mathrm{O}$ & $S$ & $\mathrm{O}$ & $S$ & O \\
\hline \multirow[t]{2}{*}{ CM 60} & 2 August 2002 & 32 & 35 & 38 & 41 & 44 & 51 & 81 & 93 \\
\hline & 14 September 2002 & 34 & 31 & 40 & 42 & 46 & 49 & 85 & 90 \\
\hline SJ 5 & 10 January 1994 & 40 & 42 & 49 & 51 & 55 & 59 & 99 & 91 \\
\hline
\end{tabular}

DAP, days after planting.

above-ground biomass; whereas it seemed to agree quite well with observed pod weight. The statistical evaluation of the agreements between observed and simulated values using RMSEP and d values indicated good agreements for pod and total crop weight for soybean for both the 1994 dry season and the 2002 late-rainy season. The values of RMSEP and d for total crop weight ranged from 474 to $1228 \mathrm{~kg} \mathrm{ha}^{-1}$ and 0.89 to 0.99 respectively, and for pod weight ranged from 453 to $693 \mathrm{~kg} \mathrm{ha}^{-1}$ and 0.90 to 0.97 respectively. The differences between the simulated and observed values for dry weight of crop biomass and pod at harvest maturity ranged from $26 \%$ to $57 \%$ and from $18 \%$ to $66 \%$ of the observed values respectively.
Evaluation of the CSM-CROPGRO-Soybean model using the observed data sets from eight different farmers' practices in 1999 and 2000 indicated that the model overestimated for some growing conditions and underestimated for others (Table 5). The values for observed and simulated yield ranged from 436 to $1515 \mathrm{~kg} \mathrm{ha}^{-1}$ and 678 to $1556 \mathrm{~kg} \mathrm{ha}^{-1}$ respectively. The differences between observed and simulated seed yields were not considerably large for almost all growing conditions and ranged from $1 \%$ to $65 \%$ of the observed values. The RMSEP values ranged from 13 to $462 \mathrm{~kg} \mathrm{ha}^{-1}$.

The disparities between the observed and simulated values were because of the fact that the crop in the actual experiments could have been affected by weeds, diseases 
(a)

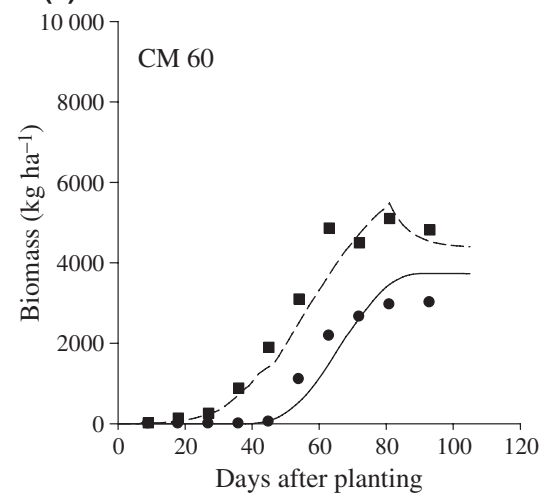

(c)

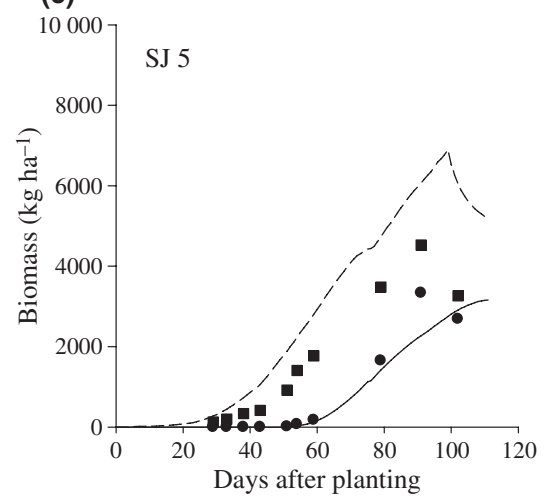

(b)

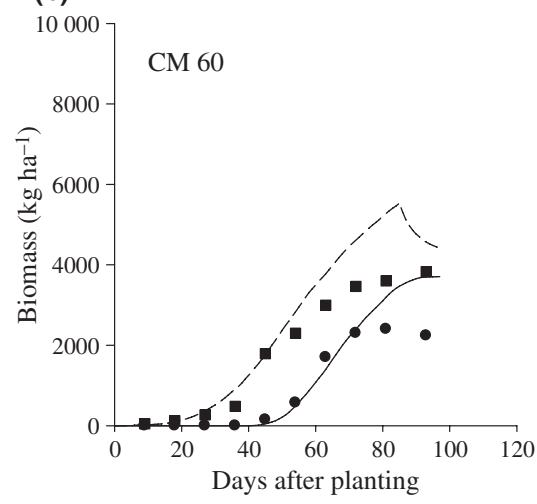

Fig. 2 A comparison of simulated (lines) and observed (symbols) values for above-ground biomass and pod weight for the soybean cultivar CM 60 planted on 2 August 2002 (a) and 14 September 2002 (b), and for the cultivar SJ 5 planted on 10 January 1994, at Chiang Mai (c) for model evaluation.

\begin{tabular}{lclllll}
\hline Planting date & $\begin{array}{l}\text { Fertilizer } \\
\left(\mathrm{kg} \mathrm{N} \mathrm{ha}^{-1}\right)\end{array}$ & $\begin{array}{l}\text { Plant density } \\
\left(\text { plants } \mathrm{m}^{-2}\right)\end{array}$ & $\begin{array}{l}\text { Observed } \\
\text { yield }\left(\mathrm{kg} \mathrm{ha}^{-1}\right)\end{array}$ & $\begin{array}{l}\text { Simulated } \\
\text { yield }\left(\mathrm{kg} \mathrm{ha}^{-1}\right)\end{array}$ & $\begin{array}{l}\text { Difference }^{\mathrm{a}} \\
(\%)\end{array}$ & RMSEP \\
\hline 18 July 1999 & 0 & 33 & 1151 & 1164 & -1 & 13 \\
30 July 1999 & 15 & 20 & 1515 & 1556 & -3 & 41 \\
23 July 1999 & 0 & 30 & 436 & 718 & -65 & 282 \\
3 August 1999 & 15 & 18 & 918 & 678 & 26 & 240 \\
7 August 2000 & 0 & 24 & 603 & 769 & -28 & 166 \\
5 August 2000 & 20 & 14 & 938 & 730 & 22 & 208 \\
23 July 2000 & 0 & 16 & 806 & 1268 & -57 & 462 \\
3 August 2000 & 20 & 16 & 1338 & 912 & 32 & 426 \\
\hline
\end{tabular}

Table 5 Model evaluation for farmers' management practices for soybean cultivar SJ 5 for the Phu Pha Man district

${ }^{a}$ (Observed yield - simulated yield) $\times 100 /$ observed yield

and pests, and other factors which were not accounted for by the model. In general, however, the results for model evaluation with the observed data sets from different farmers' practices indicated that the CSM-CROPGRO-Soybean model was able to simulate yield fairly accurately for most growing conditions as experienced in these farmers' fields in Phu Pha Man.

\section{Simulated optimum management practices}

To identify the optimum management practice for soybean production for the district of Phu Pha Man, an analysis was conducted based on the crop simulation models. The simulation scenarios suggested that a plant density of 40 plants $\mathrm{m}^{-2}$ predicted the highest average value of soybean yield over all combinations of nitrogen fertilizer rates, planting dates, soil series and years when compared with plant densities of 20 and 30 plants $\mathrm{m}^{-2}$ (Table 6). This density of 40 plants $\mathrm{m}^{-2}$ is now generally recommended by local extension for soybean production for the Phu Pha Man district.

The model predicted that the four different rates of nitrogen fertilizer application would not show much difference in average values over all combinations of planting 
Table 6 Simulated results for different management scenarios for soybean
Fig. 3 Daily average maximum temperature, minimum temperature, solar radiation and rainfall for the Phu Pha Man district (values are averaged over 32 years).

\begin{tabular}{lccll}
\hline Management & Anthesis (DAP) & Harvest (DAP) & Yield $\left(\mathrm{kg} \mathrm{ha}^{-1}\right)$ & Harvest index \\
\hline Plant density $\left(\right.$ plants $\mathrm{m}^{-2}$ ) & & & \\
20 & $37 \mathrm{~A}$ & $104 \mathrm{~A}$ & $2617.0 \mathrm{C}$ & $0.501 \mathrm{~B}$ \\
30 & $37 \mathrm{~A}$ & $104 \mathrm{~A}$ & $2718.3 \mathrm{~B}$ & $0.505 \mathrm{~A}$ \\
40 & $37 \mathrm{~A}$ & $104 \mathrm{~A}$ & $2826.1 \mathrm{~A}$ & $0.505 \mathrm{~A}$ \\
& & & \\
$\mathrm{~N}$ application & $\left(\mathrm{kg} \mathrm{N} \mathrm{ha}^{-1}\right)$ & & & \\
0 & $37 \mathrm{~A}$ & $104 \mathrm{~A}$ & $2691.4 \mathrm{~B}$ & $0.502 \mathrm{C}$ \\
10 & $37 \mathrm{~A}$ & $104 \mathrm{~A}$ & $2703.1 \mathrm{~B}$ & $0.503 \mathrm{BC}$ \\
20 & $37 \mathrm{~A}$ & $104 \mathrm{~A}$ & $2738.1 \mathrm{~A}$ & $0.504 \mathrm{~B}$ \\
30 & $37 \mathrm{~A}$ & $104 \mathrm{~A}$ & $2749.2 \mathrm{~A}$ & $0.505 \mathrm{~A}$ \\
Planting date & & & & \\
15 May $^{\mathrm{a}}$ & $41 \mathrm{~A}$ & $121 \mathrm{~A}$ & $1987.6 \mathrm{I}$ & $0.357 \mathrm{~J}$ \\
30 May $^{\mathrm{a}}$ & $40 \mathrm{~A}$ & $117 \mathrm{~B}$ & $2374.4 \mathrm{G}$ & $0.405 \mathrm{I}$ \\
15 June $^{\mathrm{a}}$ & $39 \mathrm{~B}$ & $111 \mathrm{C}$ & $2703.4 \mathrm{E}$ & $0.453 \mathrm{H}$ \\
30 June $^{\mathrm{a}}$ & $37 \mathrm{D}$ & $105 \mathrm{D}$ & $2882.7 \mathrm{C}$ & $0.501 \mathrm{~F}$ \\
15 July $^{\mathrm{a}}$ & $35 \mathrm{~F}$ & $99 \mathrm{G}$ & $2785.4 \mathrm{D}$ & $0.534 \mathrm{E}$ \\
30 July $^{\mathrm{a}}$ & $33 \mathrm{G}$ & $94 \mathrm{H}$ & $2613.9 \mathrm{~F}$ & $0.565 \mathrm{C}$ \\
15 August $^{\mathrm{a}}$ & $32 \mathrm{H}$ & $89 \mathrm{I}$ & $2295.3 \mathrm{H}$ & $0.581 \mathrm{~B}$ \\
15 December $^{\mathrm{b}}$ & $39 \mathrm{~B}$ & $100 \mathrm{~F}$ & $3521.6 \mathrm{~A}$ & $0.586 \mathrm{~A}$ \\
30 December $^{\mathrm{b}}$ & $38 \mathrm{C}$ & $100 \mathrm{~F}$ & $3277.9 \mathrm{~B}$ & $0.558 \mathrm{D}$ \\
15 January $^{\mathrm{b}}$ & $36 \mathrm{E}$ & $102 \mathrm{E}$ & $2762.6 \mathrm{D}$ & $0.497 \mathrm{G}$ \\
\hline
\end{tabular}

Values in the column followed by the same letter are not significantly different at the $\mathrm{P}<0.05$ level. DAP, days after planting.

${ }^{a}$ Rainfed conditions.

b Irrigated conditions.

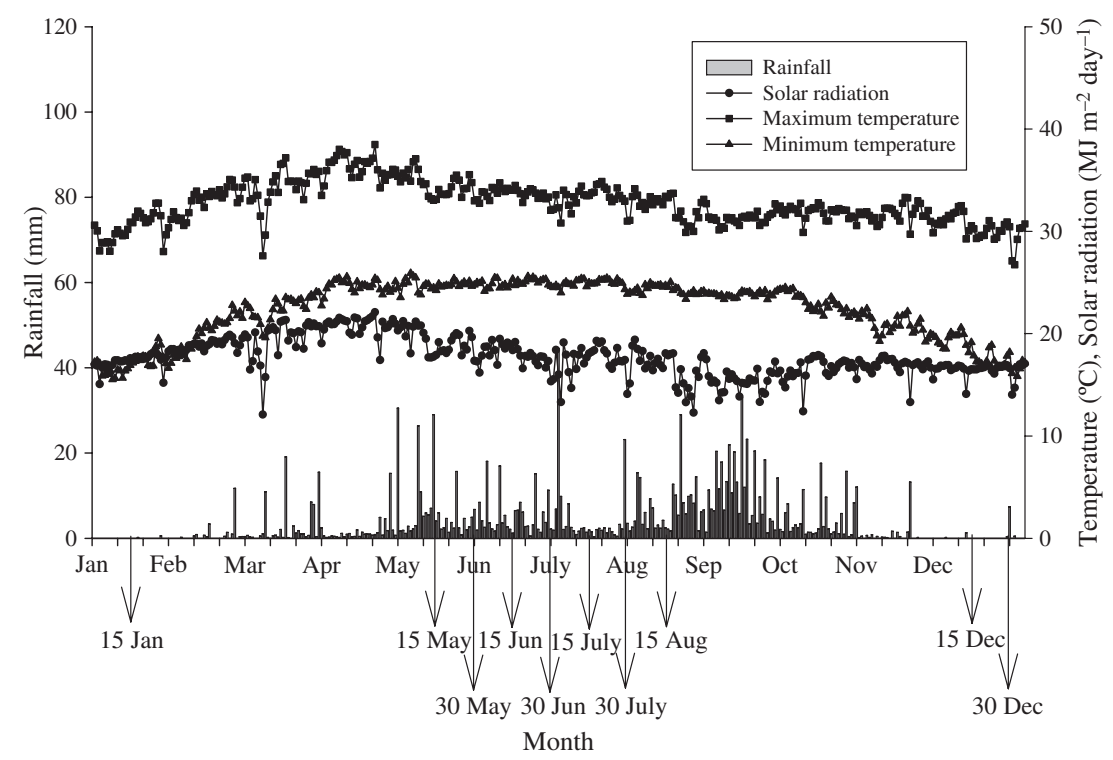

dates, rates of plant density, soil series and years for yield and harvest index, with a statistically significant difference at $\mathrm{P}<0.05$ (Table 6). This would be expected because of the effect of $\mathrm{N}_{2}$ fixation in CSM-CROPGRO-Soybean. Based on experimental experience, however, supplemental nitrogen fertilizer is still needed to improve soybean production in Phu Pha Man district, possibly because of the absence of properly functioning rhizobia required for nitrogen fixation under natural conditions. It has been reported that there is a strong interaction between genotype, soil type and inoculate on nitrogen fixation (Van Jaarsveld et al. 2002). In addition, supplemental nitrogen fertilizer could be applied as starter $\mathrm{N}$, which results in supporting $\mathrm{N}_{2}$ fixation as well as increasing plant growth 
and seed yield (Kucey et al. 1989, Tewari et al. 2004). Jefing et al. (1992) and Yinbo et al. (1997) reported that application of the minimum starter $\mathrm{N}$ at a rate of $25 \mathrm{~kg} \mathrm{~N} \mathrm{ha}^{-1}$ has been found to enhance the yield of soybean. In addition, local extension recommends that the application of supplemental nitrogen fertilizer at a rate of $20-30 \mathrm{~kg} \mathrm{~N}$ $\mathrm{ha}^{-1}$ would increase soybean yield for this region.

The analysis to determine the optimum planting date under rainfed conditions, ranging from May 15 to August 15 at 15-day intervals, showed that the early planting dates produced longer durations from planting to anthesis and harvest maturity than the later planting dates based on the average values across years and soil series (Table 6). The low amounts of daily rainfall provided insufficient moisture to the plants during the early planting dates and, therefore, delayed anthesis and harvest maturity (Fig. 3). The average seed yield and harvest index for the seven planting dates ranged from 1988 to $2883 \mathrm{~kg} \mathrm{ha}^{-1}$ and 0.357 to 0.581 respectively (Table 6). The June 30 planting date resulted in the highest average seed yield and the August 15 planting date resulted in the highest value for the harvest index. The average seed yield for these seven different planting dates for the soybean cultivar CM 60 ranged from 2061 to $2791 \mathrm{~kg} \mathrm{ha}^{-1}$, with a variation (standard deviation; S.D.) between 370 and $846 \mathrm{~kg} \mathrm{ha}^{-1}$. For the soybean cultivar SJ 5, the average seed yield for seven different planting dates ranged from 1915 to $2974 \mathrm{~kg} \mathrm{ha}^{-1}$, with a S.D. between 409 and $864 \mathrm{~kg} \mathrm{ha}^{-1}$. An average high yield for the cultivar CM 60 $\left(>2618 \mathrm{~kg} \mathrm{ha}^{-1}\right)$ was obtained for the planting dates 15 June 15 to 15 July. For the cultivar SJ 5, an average high yield $\left(>2789 \mathrm{~kg} \mathrm{ha}^{-1}\right.$ ) was obtained for 15 June to 30 July planting dates. The range of simulated yield around the median for the high-yielding planting dates was smaller than that for the other planting dates (Fig. 4). A high amount of rainfall for the entire growing season and high values for solar radiation during pod development (Fig. 3) contributed to the high yield levels for these planting dates, and they are the most productive planting dates for soybean under rainfed conditions.

Based on a comparison of the simulated results for three different planting dates under irrigated conditions during the dry season from 15 December to 15 January of the following year, the durations from planting to anthesis and harvest maturity for the three different planting dates were about the same. Average seed yield and harvest index for the three different planting dates ranged from 2763 to $3522 \mathrm{~kg} \mathrm{ha}^{-1}$ and 0.497 to 0.586 respectively (Table 6). The 15 December planting date resulted in the highest average seed yield and had the highest value for the harvest index. Average seed yield for the three different planting dates for the cultivar CM 60 ranged from 2753 to $3472 \mathrm{~kg} \mathrm{ha}^{-1}$, with S.D. values between 370 and $610 \mathrm{~kg} \mathrm{ha}^{-1}$. For the soybean
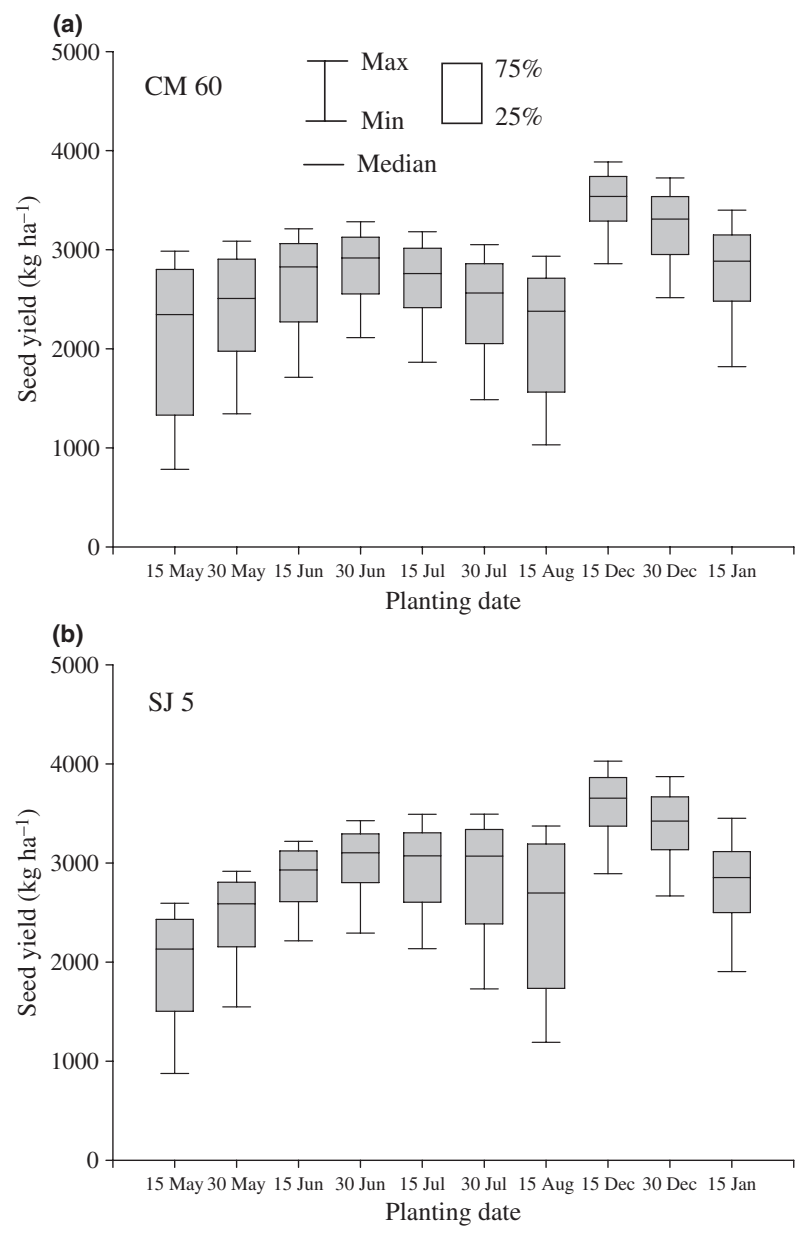

Fig. 4 Simulated seed yield for the soybean cultivars CM 60 (a) and SJ 5 (b) as a function of different planting dates. The simulated results for each planting date were obtained from the combination of historical weather data for 32 years, three plant densities, four nitrogen fertilizer application rates and seven different soils of the Phu Pha Man district.

cultivar SJ 5, average seed yield for the three planting dates ranged from 2772 to $3571 \mathrm{~kg} \mathrm{ha}^{-1}$, with S.D. values between 409 and $544 \mathrm{~kg} \mathrm{ha}^{-1}$. Simulated seed yields for both CM 60 and SJ 5 on different planting dates are given in Fig. 4. The 15 December planting date resulted in the highest yield for both cultivars, with a smaller range between the extremes compared with that for the other two planting dates. This indicates that the 15 December planting date is expected to be the most suitable planting date for producing soybean under well-irrigated conditions during the dry season.

\section{Conclusions}

The results for model calibration showed that the genetic coefficients for the two soybean cultivars resulted in simulated development and growth parameters that were in 
good agreement with their corresponding observed values for almost all parameters. For model evaluation, there was a good agreement between simulated and observed data for phenology and growth of soybean. Therefore, we concluded that the CSM-CROPGRO-Soybean model can be successfully used for simulating growth and yield for soybean for local environments in Thailand.

This study also showed the potential of the model to serve as a tool for determining optimum management practices for soybean for growing conditions in the Phu Pha Man district. The model simulations showed that the June 15 , June 30 and July 15 planting dates resulted in the highest soybean yield levels when compared with the other planting dates for the rainy season. The December 15 planting date resulted in the highest soybean yield under irrigated conditions for the dry season for the cultivars CM 60 and SJ 5. Increasing supplemental nitrogen fertilizer from 0 to $30 \mathrm{~kg} \mathrm{~N} \mathrm{ha}^{-1}$ can slightly increase soybean yield. Similar results were found when the soybean plant density was increased from 20 to 40 plants $\mathrm{m}^{-2}$.

This study demonstrated how the CSM-CROPGROSoybean model could potentially assist in determining optimum crop management practices for tropical regions such as Thailand. It is clear that the model could provide valuable information to design suitable agricultural management practices for increasing soybean production for Phu Pha Man district. This study showed the potential for using a crop simulation model as an information technology tool for determining suitable management schemes for soybean production in the other agricultural production areas in Thailand and other countries in Southeast Asia. However, we suggest that, to be able to identify the optimum crop management practices for a specific region, the results both from a few years of actual experiments and from long-term simulations should be used to help design the best recommendation.

\section{Acknowledgements}

This work was supported by a grant from the US Agency for International Development between the University of Georgia and the International Crops Research Institute for the Semi-Arid Tropics (ICRISAT), and was conducted in collaboration with Khon Kaen University, Khon Kaen, Thailand.

\section{References}

Aggarwal, P. K., and N. Kalra, 1994: Analyzing the limitation set by climatic factors, genotype, and water and nitrogen availability on productivity of wheat: II. Climatically potential yields and management strategies. Field Crops Res. 36, 161-166.
Anothai, J., A. Patanothai, S. Jogloy, K. Pannangpetch, K. J. Boote, and G. Hoogenboom, 2008: A sequential approach for determining the cultivar coefficients of peanut lines using end-of-season data of crop performance trials. Field Crops Res. 108, 169-178.

Banterng, P., A. Patanothai, K. Pannangpetch, S. Jogloy, and G. Hoogenboom, 2003: Seasonal variation in the dynamic growth and development traits of peanut lines. J. Agric. Sci. 141, 51-62.

Banterng, P., A. Patanothai, K. Pannangpetch, S. Jogloy, and G. Hoogenboom, 2006: Yield stability evaluation of peanut lines: a comparison of an experimental versus a simulation approach. Field Crops Res. 96, 168-175.

Boote, K. J., and M. Tollenaar, 1994: Modeling genetic yield potential. In: K. J. Boote, J. M. Bennett, T. R. Sinclair, and G. M. Paulsen, eds. Physiology and Determination of Crop Yield, pp. 533-565. ASA-CSSA-SSSA, Madison, WI.

Boote, K. J., J. W. Jones, G. Hoogenboom, and N. B. Pickering, 1998: Simulation of crop growth: CROPGRO model. In: G. Y. Tsuji, G. Hoogenboom, and P. K. Thornton, eds. Understanding Options for Agricultural Production, pp. 99-128. Kluwer Academic Publishers, London.

Chapman, C. S., G. L. Hammer, D. G. Butler, and M. Cooper, 2000: Genotype by environment interactions affecting grain sorghum. III: temporal sequences and spatial patterns in the target population of environments. Aust. J. Agric. Res. 51, 223-233.

Egli, D. B., and W. Bruening, 1992: Planting date and soybean yield: evaluation of environmental effect with a crop simulation model: SOYGRO. Agric. For. Meteorol. 62, 19-29.

Geng, S., C. E. Hess, and J. Auburn, 1990: Sustainable agricultural systems: concepts and definitions. J. Agron. Crop Sci. 165, 73-85.

Hoogenboom, G., J. W. Jones, and K. T. Boote, 1992: Modeling growth, development, and yield of grain legumes using SOYGRO, PNUTGRO, and BEANGRO: a review. Trans. ASAE 35, 2043-2056.

Hoogenboom, G., P. W. Wilkens, and G. Y. Tsuji (eds), 1999: DSSAT Version 3, Volume 4. University of Hawaii, Honolulu, HI.

Hoogenboom, G., J. W. Jones, P. W. Wilkens, C. H. Porter, W. D. Batchelor, L. A. Hunt, K. J. Boote, U. Singh, O. Uryasev, W. T. Bowen, A. J. Gijsman, A. S. Du Toit, J. W. White, and G. Y. Tsuji, 2004: Decision Support System for Agrotechnology Transfer Version 4.0. [CD-ROM]. University of Hawaii, Honolulu, HI.

Hunt, L. A., S. Pararajasingham, and J. V. Wiersma, 1996: Effects of planting date on the development and yield of spring wheat: simulation of field data. Can. J. Plant Sci. 76, 51-58.

IBSNAT (International Benchmark Sites Network for Agrotechnology Transfer Project), 1988: Technical Report 1. Experimental Design and Data Collection Procedure for IBSNAT. The Minimum Data Sets for Systems Analysis and Crop Simulation, 3rd edn. University of Hawaii, Honolulu, HI. 
Jefing, Y., D. F. Herridge, M. B. Peoples, and B. Rerkasem, 1992: Effects of $\mathrm{N}$ fertilization on $\mathrm{N}_{2}$ fixation and $\mathrm{N}$ balances of soybean grown after lowland rice. Plant Soil 147, 235-242.

Jones, J. W., G. Hoogenboom, C. H. Porter, K. J. Boote, W. D. Batchelor, L. A. Hunt, P. W. Wilkens, U. Singh, A. J. Gijsman, and J. T. Ritchie, 2003: The DSSAT cropping system model. Eur. J. Agron. 18, 235-265.

Kucey, R. M. N., P. Chaiwanakupt, N. Boonkerd, P. Sanitwongse, C. Siripaibool, P. Wadisirisuk, and T. Arayangkool, 1989: Nitrogen fixation (N-15 dilution) with soybeans under Thai field conditions. IV. Effect of $\mathrm{N}$ addition and Bradyrhizobium japonicum inoculation in soils with indigenous B. japonicum populations. J. Appl. Bacteriol. 67, 137-144.

Meinke, H., and G. L. Hammer, 1995: A peanut simulation model: II. Assessing regional production potential. Agron. J. 87, 1093-1099.

Meinke, H., G. L. Hammer, and S. C. Chapman, 1993: A sunflower simulation model: II. Simulating production risks in a variable subtropical environment. Agron. J. 85, 735-742.

Penning de Vries, F. W. T., P. Teng, and K. Metselaar (eds), 1993: Systems Approaches for Agricultural Development. Kluwer Academic Publishers, Dordrecht, the Netherlands.

Phakamas, N., A. Patanothai, K. Pannangpetch, S. Jogloy, and G. Hoogenboom, 2008a: Dynamic patterns of components of genotype $\mathrm{x}$ environment interaction for pod yield of peanut over multiple years: a simulation approach. Field Crops Res. 106, 9-21.

Phakamas, N., A. Patanothai, K. Pannangpetch, S. Jogloy, and G. Hoogenboom, 2008b: Seasonal responses and genotypeby-season interactions for the dynamic growth and development traits of peanut. J. Agric. Sci. 146, 311-323.

Ritchie, J. T., 1998: Soil water balance and plant water stress. In: G. Y. Tsuji, G. Hoogenboom, and P. K. Thornton, eds. Understanding Options for Agricultural Production, pp. 41-54. Kluwer Academic Publishers, London.

Soler, C. M. T., G. Hoogenboom, P. C. Sentelhas, and A. P. Duarte, 2007a: Growth analysis of maize grown off-season in a subtropical environment under rainfed and irrigated conditions. J. Agron. Crop Sci. 193, 247-261.

Soler, C. M. T., P. C. Sentelhas, and G. Hoogenboom, 2007b: Application of the CSM-CERES-Maize model for planting date evaluation and yield forecasting for maize grown off-season in a subtropical environment. Eur. J. Agron. 27, 165-177.

Tewari, K., T. Suganuma, H. Fujikake, N. Ohtake, K. Sueyoshi, Y. Takahashi, and T. Ohyama, 2004: Effect of deep placement of $\mathrm{N}$ fertilizers and different inoculation methods of Bradyrhizobia on growth, $\mathrm{N}_{2}$ fixation activity and $\mathrm{N}$ adsorption rate of field-grown soybean plants. J. Agron. Crop Sci. 190, 46-58.

Tsuji, G. Y., G. Uehara, and S. Balas (eds), 1994: DSSAT Version 3, Vols. 1-3. University of Hawaii, Honolulu, HI.

Tsuji, G. Y., G. Hoogenboom, and P. K. Thornton (eds), 1998: Understanding Options for Agricultural Production. Systems Approaches for Sustainable Agricultural Development. Kluwer Academic Publishers, Dordrecht, the Netherlands.

Van Jaarsveld, C. M., M. A. Smit, and G. H. J. Krüger, 2002: Interaction amongst soybean [Glycine max (L.) Merrill] genotype, soil type and inoculants strain with regard to $\mathrm{N}_{2}$ fixation. J. Agron. Crop Sci. 188, 206-211.

Wallach, D., and B. Goffinet, 1987: Mean squared error of prediction in models for studying ecological and agronomic systems. Biometrics 43, 561-573.

White, J. W., G. Hoogenboom, J. W. Jones, and K. J. Boote, 1995: Evaluation of dry bean model Beangro V1.01 for crop production research in a tropical environment. Exp. Agric. 31, 241-254.

Willmott, C. J., 1982: Some comments on the evaluation of model performance. Bull. Am. Meteorol. Soc. 63, 1309-1313.

Yinbo, G., M. B. Peoples, and B. Rerkasem, 1997: The effect of $\mathrm{N}$ fertilizer strategy on $\mathrm{N}_{2}$ fixation, growth and yield of vegetable soybean. Field Crops Res. 51, 221-229. 
This document is a scanned copy of a printed document. No warranty is given about the accuracy of the copy. Users should refer to the original published version of the material. 